\title{
MOTIVACÃO PARA APRENDER: VALIDAÇĀO DUM PROGRAMA DE ESTRATÉGIAS PARA ADOLESCENTES COM INSUCESSO ESCOLAR
}

\section{Margarida Pocinho}

CDD: 370.154

\section{RESUMO}

Este artigo apresenta a concepção e validação dum Programa de estratégias de motivação para a aprendizagem para adolescentes com insucesso escolar. Trata-se duma pesquisa quasi-experimental, com pré e pós-teste, grupos de controle (GC) e experimental (GE), na faixa etária dos 14-15 anos a frequentar o $9^{\circ}$ ano de escolaridade. Avaliou-se o efeito do programa na auto-estima, atribuições causais de sucesso, hábitos de estudo, rendimento escolar e opiniões dos professores. O programa inclui também perfis de interesses profissionais dos alunos. Inclui ainda perfis dos professores que melhor podem motivar os alunos para aprender, tendo em conta as variáveis acima descritas. O GE $(n=110)$ melhorou significativamente comparativamente ao GC $(n=99)$ indicando que o Programa traz benefícios em termos de motivação para aprender escolares e, consequentemente, benefícios em termos de sucesso académico e pessoal, nomeadamente, aos estudantes portugueses com insucesso escolar.

\section{PALAVRAS-CHAVE}

Motivação; Aprendizagem; Insucesso escolar

\section{LEARNING MOTIVATION: VALIDATION OF A MOTIVATION LEARNING STRATEGIES PROGRAM FOR ADOLESCENCES WITH LOW ACHIEVEMENT}

\begin{abstract}
This article presents a motivation learning strategies program for promoting the academic success of adolescents with low achievement. This is a quasi-experimental research, with pre and post-test, and with an experimental group $(n=110)$ and control group $(n=99)$ carried out with $9^{\text {th }}$ grade, $14-15$ years old students. The program effects were evaluated on self-esteem, study methods, causal attributions, school achievement and opinion of the teachers. This Program also includes adolescent's vocational interests and teacher profiles to motivate students to learn better. The EG improved significantly when compared to the CG indicating that the Program can bring benefits for learning motivation and, consequently, for academic and personal success of Portuguese students facing academic insuccess.
\end{abstract}

\section{KEYWORDS}

Motivation; Learning; School low achievement 


\section{PESQUISA \\ Área Temática: Ensino de Psicologia \& Psicologia Educacional \\ Número Especial: Motivação}

\section{INTRODUÇÃO}

O conceito de motivação tem dado origem a numerosos estudos e interpretações que, por sua vez, suscitaram diferentes correntes, teorias e modelos, como formas de enquadrar, sistematizar e fundamentar o acto de aprender (HIDI; HARACKIEWICZ, 2000; ABREU, 2005). O modelo behaviorista enquadra as teorias do reforço, consideradas marcos no quadro da Psicologia Educacional e que, apesar de muito criticadas, têm tido aplicações pedagógicas importantes (CANAVARRO, 1999). No campo motivação e da aprendizagem, as teorias behavioristas proporcionam uma base sistemática de investigação, avaliação e diagnóstico, motivação, controlo do comportamento e ensino directivo (LERNER, 1997). O modelo cognitivista, por seu turno, debruça-se sobre os processos de memória e resolução de problemas, investindo no estudo das formas complexas de aprendizagem, que implicam o "aprender a aprender e a pensar", e que procuram clarificar o papel dos processos motivacionais e metacognitivos, das aprendizagens prévias e dos hábitos de estudo na aprendizagem (AUSUBEL, 2003). A aprendizagem, num ambiente cognitivista é como um processo activo e construtivo, mediatizado internamente, de recepção, processamento e transformação das experiências interactivas do sujeito (PRESSLEY; WOLOSHYN, 1995, SCHUTZ; DAVIS; SCHWANENFLUGEL, 2002).

Estar motivado para aprender pressupõe a promoção nos alunos de estratégias de auto-regulação ou de metacognição e tem sido assunto objecto de numerosas intervenções educativas, o que mostra a importância dos processos motivacionais, não descurando os cognitivos, no desempenho duma aprendizagem com significado. Investigações recentes indicam que é, igualmente, necessário que o aluno possua um conhecimento das suas capacidades, acompanhado por sentimentos de auto-estima positiva que o permita usar as melhores estratégias para aprender eficazmente (POCINHO; CANAVARRO, 2009).

Neste contex to teórico, o objectivo deste estudo consiste na concepção e validação do dum programa de estratégias de motivação para a aprendizagem promotor do sucesso académico de adolescentes com insucesso escolar, através de estratégias de promoção da auto-estima, implementação de melhores hábitos de estudo e clarificação de atribuições causais. O objectivo deste programa é promover a motivação para aprender e com isto melhorar o sucesso escolar, ou seja, melhorar as competências motivacionais destes alunos 
face às exigências do currículo escolar que enfrentam. Investigações recentes sugerem que as estratégias de motivação para a aprendizagem se devem centrar na auto-estima e nas atribuições causais do sucesso, por um lado, e nos hábitos de estudo, por outro, tendo já sido comprovada a sua influência no rendimento escolar (MUELLER; FLEMING, 2001; EDWARDS; HARWOOD, 2003; POCINHO; 2004, POCINHO; COELHO; SILVA, 2007, POCINHO et al., 2007, POCINHO; CANAVARRO, 2009).

De um modo geral, as atribuições dos alunos condicionam o seu nível de esforço e de persistência na aprendizagem e, em última instância, o seu grau de motivação (POCINHO et al., 2007). As explicações que os sujeitos dão para o seu sucesso ou insucesso têm constituído objecto de estudo da Psicologia, no âmbito da Teoria da Atribuição Causal de Weiner (WEINER, 1986; 1990). Tais atribuições podem ser descritas segundo três dimensões causais bipolares: locus, estabilidade e controlabilidade (FARIA, 1998; MASCARENHAS; ALMEIDA; BARCA, 2005). Locus de causalidade - externa vs interna - refere-se à localização da causa do sucesso ou fracasso, que pode ser interna ou externa, ou seja, dentro ou fora do sujeito; estabilidade - estável vs instável - diz respeito à temporalidade da causa, que pode mudar com o tempo (instável) ou não (estável); e a controlabilidade - controlável vs incontrolável refere-se ao grau de controlo que o sujeito tem sobre uma determinada causa. Se o aluno explica um bom resultado através de causas internas, então experimentará sentimentos positivos. Por outro lado, se a atribuição do sucesso ou insucesso se deve a causas controláveis, como o esforço, o aluno sente-se mais motivado para alcançar os seus objectivos (FARIA, 1998).

A investigação sugere que os bons alunos desenvolvem atribuições causais internas, explicando os seus elevados resultados com base na capacidade e esforço dispendido, atribuindo os seus baixos resultados ao pouco esforço (POCINHO et al., 2007). Os maus alunos, por sua vez, atribuem os seus melhores resultados à sorte e os baixos resultados à falta de capacidade ou a falta de sorte (ALMEIDA et al., 2006). Uma das razões para esta associação entre atribuições e rendimento estará em que os bons alunos ao atribuírem as causas do seu sucesso à capacidade e esforço, tendem a desenvolver abordagens de aprendizagem profunda e auto-regulada. Ao contrário, quando os alunos tendem a explicar os seus resultados escolares com base na sorte ou noutras causas externas, tendem a desenvolver abordagens de aprendizagem superficial (ROSÁRIO; FERREIRA; CUNHA, 
2003). Um padrão atribucional mal adaptado tende a explicar o fracasso escolar com base em causas internas e estáveis, assim como os desempenhos positivos a causas externas e instáveis, conduzindo o aluno a duvidar das suas capacidades e competências de aprendizagem (MASCARENHAS; ALMEIDA; BARCA, 2005). Quase sempre, estes últimos alunos acabam por desenvolver e apresentar níveis baixos de auto-conceito académico, desmotivação escolar e sentimentos de desânimo. Ao mesmo tempo, ocorre ainda que quando os maus resultados são atribuídos a causas externas, por exemplo ao professor ou à sorte, este estilo atribucional funciona como uma protecção da auto-estima do aluno perante o insucesso. Daí que a auto-estima dos maus alunos com atribuições externas se aproxima da dos bons alunos com atribuições internas (SENOS, 1996).

Para além da influência da auto-estima e das atribuições causais na motivação para aprender, se o aluno não possui hábitos de estudo, não atinge o sucesso esperado, e fica desmotivado para a aprendizagem. É sabido que os alunos possuem diferentes estilos e preferências quanto ao modo de aprender. Uns gostam mais de estudar sozinhos, outros acompanhados; com ou sem adultos; em casa ou na biblioteca. Os professores também possuem diferentes estilos de ensino: mais ou menos expositivo, com ou sem audiovisuais, com mais ou menos participação dos alunos, tendo em conta ou não o perfil de inteligências ou o estilo cognitivo de cada aluno. Os investigadores que mais têm estudado a temática dos estilos e hábitos de estudo, sugeriram o termo abordagem à aprendizagem (approach to learning), o qual se afirmou como ponto de partida da Teoria da Abordagem dos Alunos à Aprendizagem considerando, de forma genérica, que os alunos "estudam" de forma superficial ou profunda e/ou estratégica ou de alto rendimento (ROSÁRIO; FERREIRA; CUNHA, 2003).

A abordagem à aprendizagem pressupõe, assim, que o aluno, no âmbito da relação entre motivo e estratégia, interprete as suas motivações pessoais e tenha consciência dos recursos cognitivos de que dispõe. Os alunos deverão socorrer-se de capacidades e estratégias metacognitivas, quer para determinar as condições em que a relação entre motivo e estratégia ocorre, quer para planificar, controlar, monitorizar e avaliar os seus próprios recursos cognitivos, ou seja, uma melhor gestão das estratégias de monitorização da aprendizagem, facilitando a resolução das tarefas e a consecução dos objectivos educacionais (ZIMMERMAN, 2002). 


\section{PESQUISA \\ Área Temática: Ensino de Psicologia \& Psicologia Educacional Número Especial: Motivação}

\section{MÉTODO}

A nossa hipótese geral é a de que a participação num programa de estratégias de motivação para a aprendizagem irá melhorar o aproveitamento escolar, a auto-estima, as atribuições causais de sucesso e os hábitos de estudo. Para validar a eficácia do Programa, delineou-se um design quasi-experimental, com pré e pós-teste, grupo experimental (GE) e grupo de controlo (GC).

\section{Programa de estratégias de motivação para a aprendizagem}

O Programa de estratégias de motivação para a aprendizagem consistiu, assim, na aplicação de estratégias de promoção da auto-estima, e de clarificação das atribuições causais do sucesso escolar, e da promoção de hábitos de estudo, no decorrer das aulas nas várias disciplinas e em sessões extra-curriculares, com apoio de professores e de psicólogos educacionais respectivamente.

\section{Funcionamento do Programa}

Antes e após o Programa, os alunos são avaliados quanto à auto-estima, às atribuições causais, aos hábitos de estudo e aos interesses profissionais por psicólogos da Escola a que pertencem. Durante as sessões extra-curriculares, um psicólogo escolar experimenta e promove, junto dos alunos, situações de promoção da auto-estima, de atribuições causais e de hábitos de estudo, bem como estratégias de aprendizagem das matérias escolares. Durante as aulas, os professores participantes, após um programa de formação intensiva de 25 horas $^{1}$ e tendo indicações e supervisão contínua dos psicólogos escolares e da Universidade da Madeira, fazem o mesmo nas várias disciplinas. A supervisão contínua dos professores, com frequência quinzenal, durante um ano lectivo, é realizada em grupo. Aqui são expostos os acontecimentos ocorridos nas sessões dos alunos com os psicólogos e discutidas as estratégias motivacionais a aplicar nas próximas semanas.

\footnotetext{
${ }^{1}$ A colaboração e participação dos professores do GE foram creditadas na modalidade de Projecto, pelo Conselho CientíficoPedagógico da Formação Contínua, sedeado na Universidade do Minho, com o registo de acreditação CCPFC/ACC - 25972102, com supervisão da Universidade da Madeira.
} 
O objectivo das primeiras sessões foi avaliar os alunos tendo em conta as variáveis motivacionais e cognitivas necessárias para proceder à estruturação das sessões. Assim, cada aluno possuía um dossier com informação sobre o perfil de interesses, o estilo atribucional, os níveis de auto-estima e o rendimento escolar nas várias disciplinas. Este dossier estava também acessível ao psicólogo escolar, aos professores participantes e ao supervisor da Universidade da Madeira. Após avaliação, passou-se à implementação do programa de intervenção, que teve a duração de 61 sessões extra-curriculares e 75 sessões curriculares, durante um ano lectivo. Todas as variáveis cognitivas e motivacionais eram trabalhadas em cada sessão de 50 minutos. Deste modo, as variáveis cognitivas relacionavam-se com as matérias das várias disciplinas e seguiam uma sequência préestabelecida para cada conteúdo a aprender (pré-teste, contrato, modelagem, prática controlada, prática avançada, generalização e pós-teste), podendo abarcar várias sessões, consoante o ritmo dos alunos (POCINHO, 2004; POCINHO; CANAVARRO, 2009). As variáveis motivacionais eram trabalhadas em cada sessão, por meio de estratégias motivacionais globais, estratégias motivacionais tendo em conta os perfis profissionais dos alunos e estratégias motivacionais tendo em conta a auto-estima e as atribuições causais, como a seguir se descreve.

\section{Estratégias motivacionais globais}

As estratégias motivacionais adequadas pressupõem que os professores e psicólogos escolares devem manter uma atitude de aceitação das contribuições dos alunos, procurando estimular a sua colaboração activa e proporcionar sentimentos de competência escolar e pessoal face às actividades. Devem fornecer feedback acerca das contribuições de cada aluno, incentivando-o a atingir sucesso escolar, orientando o estudo e o progresso da sua aprendizagem. Esta atitude promove o seu auto-conhecimento, desenvolvendo, assim, sentimentos de competência e de controlo do seu próprio progresso, componentes essenciais ao empenhamento, interesse e persistência durante a aprendizagem, condições essenciais à motivação para aprender. Devem ser incentivadores, motivar cada um a dar o máximo de si e a desenvolver progressivamente a sua auto-estima e concepções de si próprios face ao sucesso escolar (atribuições). Estas atitudes desenvolvem a autonomia no controle do seu comportamento, como também favorecem um ambiente de comunicação e de relacionamento interpessoal afectuoso com os professores. 


\section{Estratégias motivacionais tendo em conta os perfis profissionais dos alunos}

Tratando-se do $9^{\circ}$ ano, ao longo de toda a implementação do Programa foi mantida especial atenção aos interesses vocacionais ${ }^{2}$ destes alunos. O psicólogo da escola avaliou e utilizou os perfis vocacionais para rentabilizar as sessões e motivar os alunos para a aprendizagem e, consequentemente, para atingirem o sucesso escolar. Assim, nas primeiras sessões, discutiram-se as razões que levam os alunos a estar na escola, tendo em conta os objectivos pessoais de cada um a curto, médio e longo prazo.

A orientação vocacional foi um dos aspectos que mais "energia" moveu na participação e empenho dos alunos nas sessões. O futuro profissional destes alunos constituiu um dos assuntos de discussão preferencial. Diagnosticado todo este interesse, direccionou-se o objectivo da aquisição de estratégias de aprendizagem, não só para obter resultados positivos nas disciplinas, mas também para a instrumentalização que o sucesso académico teria em todo o futuro pessoal destes alunos. Sempre que oportuno, e conhecendo a área de interesses vocacionais da maioria dos alunos, eram dados exemplos concretos da relação entre cursos e profissões e as tarefas que se iriam realizar em determinadas sessões e aulas.

\section{Estratégias motivacionais tendo em conta a auto-estima e as atribuições causais}

Nas primeiras sessões, os alunos foram solicitados a reflectir sobre as causas da auto-estima e do sucesso escolar. Através da análise das diferentes opiniões que sugeriram ${ }^{3}$, percebeu-se que as atribuições causais do sucesso escolar eram de origem externa e estariam para além do seu controle. Todas estas noções foram desmistificadas ao longo do Programa, partindo do princípio de que, através da intervenção das estratégias e do esforço de cada um, o sucesso é possível e controlável, e que depende essencialmente de si próprio.

\footnotetext{
${ }^{2}$ A grande maioria dos alunos do GE demonstra interesses pela área dos Negócios que engloba profissões que implicam elevada responsabilidade na organização, administração e funcionamento eficiente de negócios e departamentos governamentais. Incluem as finanças, a contabilidade, a gestão, a economia e a promoção comercial. Imediatamente a seguir, surge a área dos Serviços, englobando profissões que implicam responsabilidade no cuidar do bem-estar e das necessidades das pessoas, em campos como o serviço social, a protecção, o transporte, a saúde e a educação. Uma área preferencial, ainda que com menor frequência, é a da Informática, em todas as suas vertentes, desde as engenharias até ao webdesign e telecomunicações. Apesar destas duas áreas serem da preferência da maioria, o Programa teve em atenção os interesses individuais das minorias, orientando para aí, sempre que possível, os objectivos específicos das sessões. Faria (1998).

${ }^{3}$ E também por meio do Questionário de avaliação das atribuições e dimensões causais do sucesso escolar (QA) de
} 
Assim, paralelamente às actividades planeadas para cada sessão, estes conceitos foram alvo de discussão, importando salientar as influências que cada um pode ter no rendimento escolar, em particular, e no sucesso pessoal, em geral. $\mathrm{O}$ confronto das crenças acerca das atribuições causais do sucesso foi conseguido, efectivamente, depois do psicólogo ter levado os estudantes a exprimirem e a reflectirem sobre aquelas crenças e de como elas influenciariam o seu comportamento em diferentes situações académicas e de vida.

\section{Participantes}

A investigação foi realizada em Portugal, em quatro escolas públicas do Ensino Fundamental (meio urbano e meio rural), seleccionadas aleatoriamente, frequentadas por alunos de estratos sociais médios e baixos. A amostra é constituída por 209 alunos do $9^{\circ}$ ano de escolaridade, com baixo aproveitamento escolar (com 3 ou mais disciplinas com classificação abaixo da média): 108 do sexo feminino e 101 do sexo masculino, maioritariamente com $14-15$ anos de idade (34.5\% e $32.5 \%$, respectivamente), provenientes do meio urbano $(58.6 \%)$ e pertencentes a uma classe social média-baixa (63.1\%). Os 209 sujeitos que constituíam a amostra foram distribuídos aleatoriamente por dois grupos: o GE e o GC, cada um deles correspondendo a oito subgrupos, distribuídos por quatro escolas, dois subgrupos em cada uma. O programa foi aplicado a 110 alunos (GE) e o GC foi formado por 99 alunos com baixo rendimento escolar. O GC foi alvo de tratamento educativo alternativo neutro.

Os alunos não sabiam se estavam no Programa ou no tratamento neutro. Os alunos foram seleccionados através das pautas do $3^{\circ}$ período e das actas dos Conselhos de Turma. São alunos que, não tendo necessidades educativas especiais, necessitam de "aulas/sessões de apoio" por apresentarem dificuldades escolares. Colaboraram na experiência, doze professores licenciados em Línguas e Literaturas Modernas. Seis destes professores ficaram encarregados do GE, sendo um do sexo masculino e cinco do sexo feminino, de idade entre os 29 e os 45 anos. Outros seis ficaram encarregados do GC, todos do sexo feminino, de idades entre os 31 e os 49 anos. 


\section{Instrumentos}

Para a recolha de dados, utilizaram-se duas baterias de instrumentos: a primeira para caracterizar a amostra de alunos; a segunda, como medida de pré e pós-teste. A primeira bateria foi constituída por um questionário de dados biográficos acerca da idade, sexo, meios de proveniência ou residência e estatuto socioeconómico. A segunda bateria incluiu medidas pré (antes) e pós-teste (depois) e foi composta pelos seguintes instrumentos: (1) Self-Perception Profile For Adolescents; (2) Questionário de Atribuições (QA); (3) Inventário de Hábitos de Estudo (IHE) e (4) Aproveitamento escolar. Para a avaliação da opinião dos professores utilizou-se a entrevista semi-estruturada.

O Self-Perception Profile For Adolescents (HARTER, 1988), adaptado por Martins, Peixoto, Mata e Monteiro (1995) é constituído por nove subescalas, cada uma com cinco itens. A atribuição do valor 4 nesta escala corresponde a um auto-conceito elevado, e o valor 1 corresponde a um auto-conceito baixo. Por isso, quanto maior a pontuação em cada subescala, maior será o auto-conceito e dará uma auto-estima global mais elevada. A consistência interna é aceitável em todas as subescalas, com valores de alpha de Cronbach a variar entre 0.545 e 0.774 .

O IHE de Barros (1997) permite avaliar os hábitos de estudo que cada aluno adopta segundo 4 subescalas: condições ambientais de estudo, planificação, utilização de materiais e assimilação de conteúdos. Contem uma escala de sinceridade ou de desejabilidade social para controle da veracidade das respostas dadas. Quanto maior a pontuação em cada subescala melhor serão os hábitos de estudo. Os valores de alpha de Cronbach situam-se entre os 0,64 e os 0,75 e pode-se concluir que o IHE possui consistência interna aceitável.

Para a avaliação das atribuições causais utilizou-se o QA de Faria, (1998), constituído por 3 escalas: locus de causalidade; estabilidade e controlabilidade. Para cada escala, os itens são avaliados numa escala de Likert de 4 pontos, sendo 1 atribuído a atribuições menos realistas e 4 mais realistas para a subescala locus e o contrário para as subescalas estabilidade e controlabilidade. Os coeficientes alpha de Cronbach situam-se entre 0.74 e 0.89 , podendo-se concluir que o QA possui boa consistência interna. 
O aproveitamento escolar foi medido através das médias das classificações nos $1^{\circ}$ e $3^{\circ}$ períodos nas disciplinas de Língua Portuguesa, História, Geografia, Matemática, FísicaQuímica e Inglês.

\section{Procedimento}

Com o objectivo de caracterizar a amostra e realizar as medidas antes do programa (pré-testes), aplicou-se a primeira e segunda bateria de instrumentos, colectivamente, durante o horário da hora de Direcção de Turma, antes da experiência, à totalidade da amostra (N=209). Seguidamente, o Programa foi aplicado a 110 alunos (GE), que se dividiram em oito subgrupos, totalizando cerca de 60 a 75 sessões extra-curriculares, conforme a especificidade e dinâmica de cada grupo, duas sessões por semana, de 45 a 55 minutos cada uma. As sessões extra-curriculares foram complementadas pelos professores encarregados do GE, durante as suas aulas.

Na primeira sessão os alunos assinaram um contrato de aprendizagem com o psicólogo da Escola. Nas sessões seguintes foi aplicado o Programa. Após a experiência, em finais de Junho, aplicaram-se os pós-testes. Recolheram-se também as opiniões dos professores do GE.

\section{RESULTADOS}

\section{Diferenças inter-grupo antes do tratamento}

De forma a verificar possíveis diferenças entre grupos antes da intervenção, avaliamos o GE e o GC relativamente aos dados biográficos e à auto-estima, atribuições causais e hábitos de estudos de todos os alunos da amostra. A análise estatística das diferenças entre os grupos foi expressa pelos resultados obtidos após a aplicação do teste do Qui-quadrado $\left(\chi^{2}\right)$, do teste de Mann-Whitney ${ }^{4}$ e testes $t$. Não se verificaram diferenças estatisticamente significativas (nenhum p <0,05) entre o GE e o GC quanto às variáveis sexo, meio de proveniência ou residência, estatuto socioeconómico e idade.

\footnotetext{
${ }^{4} \mathrm{O}$ teste de Mann-Whitney foi utilizado para tratamento de variáveis que não seguem uma distribuição normal, segundo o teste de Kolmogorov-Smirnov.
} 
Nas classificações finais do $1^{\circ}$.período e verificou-se que também não existem diferenças estatisticamente significativas entre os grupos ( $t=-9,44 ; p>0,05)$. Quanto à avaliação da auto-estima, atribuições causais e hábitos de estudo, não se verificaram diferenças significativas entre o GE e o GC, antes da experiência (todos os p>0,05), e por conseguinte, os grupos também são equivalentes relativamente a estas variáveis (cf. Tabelas 1 a 3$)$

\section{Diferenças inter-grupo após o tratamento}

$\mathrm{Na}$ análise das possíveis mudanças na auto-estima, provocadas pela influência do Programa, começou-se por averiguar a existência de diferenças significativas entre os resultados iniciais e finais da escala, para a totalidade da amostra. Antes do tratamento, a média das pontuações obtidas nas subescalas de auto-estima, pelos sujeitos da totalidade da amostra, situava-se entre 10,39 e 14,78, valores considerados dentro dos parâmetros normais para a idade destes indivíduos (o mínimo em cada subescala é 5 e o máximo é 20). Os resultados mais elevados verificaram-se na subescala "Amizades Íntimas" e os mais baixos na subescala "Competência Atlética" (Tabela 1). Verificaram-se diferenças significativas entre o GE e o GC após a experiência em todas as subescalas $(\mathrm{p}<0,05)$, à excepção das subescalas "Competência Atlética" e “Aparência Física” ( $p>0,05)$. Ou seja, a competência académica, aceitação social, competência profissional e atitude comportamental melhoraram muito mais significativamente no GE do que no $\mathrm{GC}(\mathrm{p}<0,001)$ e o mesmo se passou com as amizades intimas e a auto-estima global $(\mathrm{p}<0,01)$. 


\section{TABELA 1}

Pontuações médias, desvios e testes t obtidos na auto-estima antes e após a experiência

\begin{tabular}{lcccccc}
\hline \multirow{2}{*}{ Subescalas } & \multicolumn{3}{c}{ Antes } & & & Após \\
& \multicolumn{1}{c}{ GE } & GC & p & GE & GC & p \\
\cline { 2 - 7 } Competência Escolar & $11,74(2,31)$ & $12,40(2,74)$ & 0,105 & $13,66(2,34)$ & $12,39(2,62)$ & 0,000 \\
Aceitação Social & $12,90(2,92)$ & $13,07(3,43)$ & 0,966 & $14,76(2,94)$ & $13,26(3,39)$ & 0,001 \\
Competência Atlética & $10,39(3,82)$ & $11,24(3,79)$ & 0,103 & $11,96(3,65)$ & $12,07(3,82)$ & 0,881 \\
Aparência Física & $13,56(3,86)$ & $13,67(4,11)$ & 0,649 & $14,95(4,14)$ & $14,45(4,21)$ & 0,376 \\
Competência Profissional & $13,98(3,16)$ & $13,59(3,36)$ & 0,292 & $15,91(3,07)$ & $14,15(3,22)$ & 0,000 \\
Atracção Romântica & $12,31(2,83)$ & $12,29(3,51)$ & 0,761 & $13,99(3,14)$ & $12,64(3,78)$ & 0,011 \\
Atitude Comportamental & $14,05(2,57)$ & $13,66(2,97)$ & 0,253 & $15,91(2,66)$ & $13,86(2,92)$ & 0,000 \\
Amizades Íntimas & $14,78(3,03)$ & $14,05(3,81)$ & 0,299 & $16,24(3,29)$ & $14,88(3,78)$ & 0,010 \\
Auto-estima & $13,82(3,19)$ & $13,92(3,36)$ & 0,902 & $15,52(3,31)$ & $13,91(3,61)$ & 0,002 \\
\hline
\end{tabular}

Quanto às atribuições causais do sucesso, antes da experiência não se verificaram diferenças significativas entre os grupos; após o tratamento, e o GE evoluiu significativamente mais do que o GC em todas as subescalas, destacando-se uma maior internalidade e um sentido de controlo do desempenho escolar mais acentuado no GE $(\mathrm{p}<0,001)$ (Tabela 2).

TABELA 2

Médias, desvios e testes t obtidos nas atribuições causais antes e depois da experiência

\begin{tabular}{|c|c|c|c|c|c|c|}
\hline \multirow{2}{*}{ Subescalas } & \multicolumn{3}{|c|}{ Antes } & \multicolumn{3}{|c|}{ Após } \\
\hline & GE & GC & $\mathbf{p}$ & GE & GC & $\mathbf{p}$ \\
\hline Locus & $51,95(6,57)$ & $52,98(5,31)$ & 0.516 & $63,14(4,46)$ & $56,75(8,46)$ & 0,000 \\
\hline Estabilidade & $36,37(10,77)$ & $34,61(9,32)$ & 0.334 & $24,10(7,57)$ & $30,11(10,90)$ & 0,000 \\
\hline Controlabilidade & $35,24(9,54)$ & $34,64(9,36)$ & 0.672 & $23,08(6,96)$ & $30,03(10,47)$ & 0,000 \\
\hline
\end{tabular}


No que se refere à análise das mudanças nos hábitos de estudo, após a experiência, o GE supera significativamente o GC (p <0,001) (Tabela 3). De facto, as condições ambientais de estudo, a planificação, a assimilação de conteúdos e a utilização de materiais melhoram significativamente mais no GE do que no GC. Finalmente, aplicou-se o teste de Mann-Whitney, e verificou-se que o aproveitamento escolar obtido no $3^{\circ}$. período pelo GE é significativamente superior ao do GC $(Z=-2,91 ; p=0,004)$.

TABELA 3

Médias e desvios obtidos nos hábitos de estudo antes e depois da experiência

\begin{tabular}{lcccccc}
\hline \multirow{2}{*}{ Subescalas } & \multicolumn{3}{c}{ Antes } & \multicolumn{3}{c}{ Após } \\
\cline { 2 - 7 } & GE & GC & p & GE & GC & p \\
\hline Condições ambientais de estudo & $14,03(4,33)$ & $14,40(3,73)$ & 0,466 & $25,81(3,88)$ & $16,68(3,73)$ & 0,000 \\
Planificação do estudo & $7,39(2,32)$ & $7,62(2,09)$ & 0,494 & $10,35(1,43)$ & $4,33(6,40)$ & 0,000 \\
Utilização de materiais & $12,91(3,32)$ & $13,08(3,50)$ & 0,832 & $20,70(3,60)$ & $13,06(2,52)$ & 0,000 \\
Assimilação de conteúdos & $11,29(3,50)$ & $10,49(3,50)$ & 0,077 & $21,47(5,87)$ & $11,48(5,31)$ & 0,000 \\
Sinceridade & $15,88(7,34)$ & $15,10(5,72)$ & 0,827 & $19,98(5,46)$ & $15,27(6,64)$ & 0,000 \\
\hline
\end{tabular}

\section{Diferenças intra-grupo}

No que respeita à auto-estima, verifica-se que houve uma evolução positiva para ambos os grupos. No entanto, é no GE que esta evolução é mais significativa, pois ela ocorre em todas as subescalas para um p <0,001. No GC, não há diferenças significativas entre "antes" e "após" a experiência nas subescalas de "Competência Escolar", "Aceitação Social", “Comportamento" e "Auto-estima" (p>0,05) (Tabela 4). 


\section{PESQUISA \\ Área Temática: Ensino de Psicologia \& Psicologia Educacional Número Especial: Motivação}

\section{TABELA 4}

Teste de Wilcoxon: análise das diferenças das pontuações obtidas nas escalas de auto-estima (intrasujeitos) antes e após a experiência

\begin{tabular}{lllll}
\hline \multirow{2}{*}{ Subescalas } & \multicolumn{3}{l}{$\mathbf{G E}$} & $\mathbf{G C}$ \\
& $\mathbf{Z}$ & $\mathbf{p}$ & $\mathbf{Z}$ & $\mathbf{p}$ \\
\hline Competência Escolar & $-8,04$ & 0,000 & $-1,56$ & 0,117 \\
Aceitação Social & $-9,18$ & 0,000 & $-1,52$ & 0,129 \\
Competência Atlética & $-7,68$ & 0,000 & $-9,00$ & 0,000 \\
Aparência Física & $-8,48$ & 0,000 & $-7,23$ & 0,000 \\
Competência Profissional & $-9,46$ & 0,000 & $-2,50$ & 0,012 \\
Atracção Romântica & $-8,05$ & 0,000 & $-3,85$ & 0,000 \\
Comportamento & $-9,95$ & 0,000 & $-1,91$ & 0,056 \\
Amizades Íntimas & $-8,373$ & 0,000 & $-8,944$ & 0,000 \\
Auto-estima & $-9,487$ & 0,000 & $-0,855$ & 0,392 \\
\hline
\end{tabular}

Analisando agora as diferenças intra-grupais verificadas entre o GE e o GC no que concerne aos hábitos de estudo, verifica-se que houve ganhos significativos em ambos os grupos relativamente às escalas "Condições ambientais de estudo" e "Planificação do Estudo" $(\mathrm{p}<0,05)($ Tabela 5).

Relativamente às outras escalas, não houve diferenças significativas entre a primeira e a segunda aplicação do IHE no GC, enquanto que no GE os alunos melhoraram significativamente os seus hábitos de estudo e de aprendizagem (todos os p <0,001).

\section{TABELA 5}

Teste de Wilcoxon: análise das diferenças das pontuações obtidas no inventário de hábitos de estudo (intra-sujeitos) antes e após a experiência

\begin{tabular}{lllll}
\hline \multirow{2}{*}{ Escalas } & \multicolumn{3}{c}{ GE } & \multicolumn{2}{c}{ GC } \\
\cline { 2 - 5 } & $\mathbf{Z}$ & $\mathbf{p}$ & $\mathbf{Z}$ & $\mathbf{p}$ \\
\hline Condições ambientais de estudo & $-8,88$ & 0,000 & $-3,07$ & 0,002 \\
Planificação do estudo & $-8,19$ & 0,000 & $-6,82$ & 0,000 \\
Utilização de materiais & $-8,75$ & 0,000 & $-0,15$ & 0,879 \\
Assimilação de conteúdos & $-8,14$ & 0,000 & $-1,19$ & 0,233 \\
Sinceridade & $-4,01$ & 0,000 & $-0,33$ & 0,737 \\
\hline
\end{tabular}


Relativamente ao aproveitamento escolar, também existem diferenças significativas intra-sujeitos, no GE, enquanto que no GC os sujeitos se mantiveram estáveis (Tabela 6).

\section{TABELA 6}

Teste de Wilcoxon: análise das diferenças intra-grupais do aproveitamento escolar do $1^{\circ}$ para o $3^{\circ}$ período

\begin{tabular}{ccc}
\hline Grupos & $\mathbf{Z}$ & $\mathbf{P}$ \\
\hline GE & $-5,98$ & 0,000 \\
GC & $-1,83$ & 0,068 \\
\hline
\end{tabular}

\section{Opiniões dos professores}

Através da análise da entrevista semi-estruturada de avaliação da evolução dos alunos, agruparam-se as opiniões dos professores em termos de participação e interesse pelas aulas, compreensão das matérias, auto-estima e atribuição do sucesso, ou seja, sentiam que os alunos estavam mais motivados para aprender. No entanto, um teste de $\chi^{2}$ mostra que a opinião dos professores sobre a evolução dos hábitos de estudo entre alunos aprovados e reprovados é diferente $\left(\chi^{2}=10,218, \mathrm{p}=0,001\right)$, o que poderá indicar que os alunos reprovados não conseguiram obter estas competências. Quanto às restantes variáveis, a opinião dos professores é o reconhecimento duma melhoria significativa na globalidade dos alunos sujeitos ao Programa.

\section{DISCUSSÃO}

No início da experiência ambos os grupos (GE e GC) eram homogéneos relativamente aos dados biográficos (idade, sexo, meio de proveniência ou residência, estatuto socioeconómico), e ao desempenho académico, avaliado a partir das classificações do $1^{\mathrm{o}}$ período. A amostra era igualmente homogénea relativamente à auto-estima, atribuições causais do sucesso e aos hábitos de estudo. 
Os resultados obtidos parecem indicar que o programa pode trazer benefícios ou efeitos positivos melhorando o aproveitamento escolar e aumentando significativamente a auto-estima, as atribuições causais e os hábitos de estudo dos alunos. Parece-nos que as variáveis componentes trabalhadas nas sessões extra-curriculares, com psicólogos educacionais, e nas aulas, com professores, tiveram efeito no equilíbrio emocional dos alunos, tanto pelos elogios e constante feedback dos professores, como também na efectiva melhoria no desempenho escolar. Adquirindo segurança na compreensão das matérias, os alunos sentem-se mais auto-confiantes, conseguindo, deste modo, aumentar o desempenho escolar, e, consequentemente, sentem-se melhor consigo próprios e com os outros, adquirindo verdadeira motivação para aprender (POCINHO, 2004; POCINHO, 2006; POCINHO; CANAVARRO, 2009).

O ensino de estratégias de motivação para a aprendizagem pode transformar-se num instrumento poderoso de promoção do sucesso académico e da qualidade do ensino/aprendizagem (PAJARES, 2002). Face às condições da experimentação e aos resultados apurados, sugere-se que este estudo constitua o ponto de partida para outras investigações que incluam um maior número de escolas, de professores e de alunos. Investigações desta natureza pressupõem o uso de instrumentos de avaliação e diagnóstico rigorosos e diversificados, das motivações, da auto-estima e das dinâmicas criadas nas sessões e na sala de aula. Uma questão que tem de ser investigada com maior profundidade é a generalização da motivação para aprender noutros contextos e situações de aprendizagem, ou seja, averiguar a permanência dos seus efeitos ao longo das diversas disciplinas não incluídas no Programa e futuros anos de escolaridade e da aprendizagem ao longo da vida.

Torna-se, ainda, importante que os psicólogos educacionais assumam as responsabilidades que lhes cabem, não só para aprofundar o estudo da motivação, como também para desenvolverem programas de intervenção que ajudem a actuar no domínio do sucesso escolar, no qual intervenções compostas por estratégias motivacionais tenham significado, em benefício da promoção da motivação para aprendizagem dos seus alunos. 


\section{REFERÊNCIAS}

ABREU, M. V. Cinco ensaios sobre a motivação. Coimbra: Livraria Almedina, 2005.

ALMEIDA, L. S. et al. Atribuições causais em contex to escolar: um novo formato de prova para a sua avaliação. In: CONFERÊNCIA INTERNACIONAL DE AVALIAÇÃO PSICOLÓGICA: FORMAS E CONTEXTOS, XI, Braga. Actas... Braga: Instituto de Educação e Psicologia - Universidade do Minho, Portugal, 2006.

AUSUBEL, D. P. Aquisição e retenção de conhecimentos: uma perspectiva cognitiva. Trad. L. Teopisto. Lisboa: Plátano Edições Técnicas, 2003.

BARROS, A. IHE - Inventário de hábitos de estudo. Lisboa: CEGOG-TEA, 1997.

CANAVARRO, J. M. Ciência e sociedade. Coimbra: Quarteto Editora, 1999.

EDWARDS, C.; HARWOOD, J. Social identity in the classroom: An examination of age identification between students and instructors. Communication Education, Georgia, v. 52, n. 1, p. 60-66, 2003.

FARIA, L. M. Desenvolvimento diferencial das concepções pessoais de inteligência durante a adolescência. Lisboa: Fundação Calouste Gulbenkian; Junta Nacional de Investigação Científica e Tecnológica, 1998.

HIDI, S.; HARACKIEWICZ, J. M. Motivating the academically unmotivated: a critical issue for the 21 st century. Review of Educational Research, Washington, v. 70, n. 2, p. 151-179, 2000 .

LERNER, J. W. Learning disabilities: theories, diagnosis, and teaching strategies. 7. ed. Boston; New York: Houghton Mifflin Company, 1997.

MARTINS, M. A.; PEIXOTO, F.; MATA, L.; MONTEIRO, V. Escala de auto-conceito para crianças e pré-adolescentes de Susan Harter. Provas Psicológicas em Portugal, Braga, v. 1, p. 79-89, 1995.

MASCARENHAS, S.; ALMEIDA, L. BARCA, A. Atribuições causais e rendimento escolar: impacto das habilitações literárias dos pais e do género dos alunos, Revista Portuguesa de Educação, Coimbra, v. 18, n. 1, p. 77-91, 2005.

MUELLER, A.; FLEMING, T. Cooperative learning: listening to how children work at school. The Journal of Educational Research, Washington, v. 94, n. 5, p. 259, 2001.

PAJARES, F. Gender and perceived self-efficacy in self-regulated learning. Theory into Practice, Ohio, v. 41, n. 2, 116-127, 2002. 
POCINHO, M. D. et al. Atribuições causais para o bom e fraco desempenho escolar: estudo com alunos do $3^{\circ}$ ciclo do ensino básico. Revista Psicologia, Educação e Cultura, Porto, v. 11, n. 2, 2007.

Psicologia cognitiva e língua materna: avaliação da eficácia dum programa de estratégias de aprendizagem para alunos com insucesso escolar em língua portuguesa. 2004. Tese (Doutorado em Educação) - Universidade da Madeira, Funchal, Portugal, 2004.

. Resultados obtidos a partir dum Programa de Estratégias de Compreensão (PEC) para alunos do $9^{\circ}$ ano de escolaridade com insucesso escolar em Língua Portuguesa. Educare/Educere, Castelo Branco, v. 11, n. 19, p. 139-160, 2006.

POCINHO, M. D.; COELHO, C. S.; SILVA, C. F. O ensino de estratégias de expressão escrita a alunos do $9^{\circ}$ ano de escolaridade, Psicologia e Educação, Évora, v. 6, n. 1, p. 63-82, 2007.

POCINHO, M. D.; CANAVARRO, J. M. Sucesso escolar e estratégias de compreensão e expressão verbal: como compreender melhor as matérias e as aulas. Lisboa: PEDAGO, 2009.

PRESSLEY, M.; WOLOSHYN, V. Cognitive strategy instruction that really improves children's academic performance. 2. ed. Cambridge; Massaschusetts: Brookline Books, 1995.

ROSÁRIO, P. S., FERREIRA, I., CUNHA, Â. Inventário de processos de estudo (I.P.E.). In: MACHADO, C. (Ed.). Avaliação psicológica: instrumentos validados para a população portuguesa. Coimbra: Quarteto Editora, 2003, p. 15-34.

SCHUTZ, P. A.; DAVIS, H. A.; SCHWANENFLUGEL, P. J. Organizations of concepts relevant to emotions and their regulation during test taking. The Journal of Experimental Education, Washington, v. 70, n. 4, p. 316-336, 2002.

SENOS, J. Atribuição causal, auto-estima e resultados escolares. Análise Psicológica, Lisboa, v. 1, n. 14, p. 111-121, 1996.

WEINER, B. An attributional theory of motivation and emotion. New York: SpringerVerlag, 1986.

WEINER, B. History of motivational research in education. Journal of Educational Psychology, Washington, v. 82, p. 616-622, 1990.

ZIMMERMAN, B. J. Becoming a self-regulated learner: An overview. Theory into Practice,Ohio, v. 41, n. 2, p. 64-72, 2002. 
Psicóloga e Mestre em Psicologia da Educação pela Universidade de Coimbra (UC), Portugal; Ph.D em Educação pela Universidade da Madeira (UMa), Portugal; Professora Auxiliar do Departamento de Psicologia e Estudos Humanísticos da UMa; Membro do Grupo de Estudos e Pesquisas do Instituto de Psicologia Cognitiva, Desenvolvimento Vocacional e Social da UC (IPCDVS da UC), Membro do Programa de Pós Graduação em Psicologia da Educação da UMa. E-mail: mpocinho@uma.pt

Recebido em: 20/07/2009

Publicado em: 30/10/2009 